\title{
SERVQUAL Model with Interrelated Dimensions. The Case of The Pharmacy in Mexico
}

\author{
Fernando Rojas ${ }^{1 *}$, Giuliani Coluccio ${ }^{2}$
}

\begin{abstract}
This research is focused on understanding the interrelation between the different dimen-sions of the SERVQUAL model in the pharmaceutical area, which have differences in per-ceptions of service domains depending on the cultures in which they are immersed.

To study the proposed relationships, we collect data of 100 pharmacy customers of Mex- ico and use SEM to test the relationship between SERVQUAL dimensions, purchase fre- quency, gender, and quality perception.

Our results show that the SERVQUAL dimensions are interrelated, SERVQUAL dimen-sions and gender predict the perception of quality but not the purchase frequency. These results provide key information in order to understand in a better way the service quality inthe pharmaceutical area. We develop a theoretical framework that is based on interrelationships between the dif-ferent dimensions of SERVQUAL, assuming that they are not independent of each other. This way of understanding SERVQUAL dimensions can provide relevant information to un-derstand better how individual perceptions affect the service quality in the pharmaceutical area.
\end{abstract}

Keywords: interrelated dimensions; Mexican culture, relationships; SEM, SERVQUALmodel

Submitted: May $17^{\text {th }}, 2021 /$ Approved: August $24^{\text {th }}, 2021$

\section{Introduction}

The quality of service perceived by users in health is an important concept for organizations and constitutes a measure of performance obtained from the organizational strategies carried outto improve service systems (Tzeng and Chang, 2011).

Service quality is a classic area of research in management and marketing science. However,its specific application to the pharmaceutical area is low. This is because the research in dimen-sion of pharmaceutical service quality are few and not evaluated the impact of these dimensions. This leaves a great field to explore due to the characteristics and effects that the consumption ofthe different products that a pharmacy sells can cause to users, public administration and society (Rojas et al., 2018).

Understanding the quality of service is key to being able to improve the management within the organizations. Grönroos (2020) points out that quality of service is the result of an evaluation process where the consumer compares their expectations with the perceived service when they receive it. Due to the amplitude and generalization of this definition, several authors have tried to develop a consistent instrument that can measure this variable. However, because of its complexity, there is no general agreement, and over time this variable has been interpreted in different ways (Um, 2018). In health, the SERVQUAL model is structured in functional quality (Fatima et al., 2018). In this context, the client's perceptions about the quality of the service result from a comparison of their pre-service expectations with their actual service experience. Based on this perspective, different scales have been developed for the measurement of service quality, which are mainly known as SERVQUAL (Haming et al., 2019). Five dimensions of service quality apply to organizations providing services in general (Shafiq et al., 2017): (i) tangibility, that is, physical facilities, equipment and staff appearance; (ii) fiability, that is, the ability to perform the promised service in a reliable and accurate manner; (iii) guarantee, that is, knowledge, courtesy and ability of employees to instill trust in the client towards the service provider; (iv) responsibil- ity, that is, the willingness to help customers and provide a fast service; and (v) empathy, that is, the provision of personalized and individualized customer service (Zeithaml et al., 2020). How- ever, these five dimensions of SERVQUAL are generally assumed as orthogonal and independent constructs, whose relationships are exploitable through structural equation models (SEM), which up to now has implied the proposal of models without interrelations.

The aim of this study is to describe relationships between constructs, considering the quality

of service as a latent dependent variable, determined by a sequence of interrelationships between the tangible elements that determine empathy, and finally security, as necessary elements to reach a response in the quality of service perceived by users in the pharmaceutical area. This paper is organized as follows: Section 2 is a literature review about of quality of service adapted to phar- maceutical area in the Mexican market. Section 3 exposes the proposed methodology, whereas Section 4 illustrates it with a real-world case study in the Mexican pharmaceutical area; and Section 5 provides discussions, conclusions to the results obtained in this study, as well as their limitations and future research.

(1) Faculty of Pharmacy, School of Nutrition and Dietetics, Universidad de Valparaíso, Chile

(2) Facultad de Ingeniería, Departamento de Ingeniería Industrial y Sistemas, Universidad de Tarapacá, Chile

*Corresponding author: fernando.rojas@uv.cl 


\section{Literature review}

The service marketing literature devoted much attention to the relationship between perceivedquality service and customer satisfaction as a component of "loyalty chain", see Vatjanasare- gagul (2019) and Song and $\mathrm{Qu}$ (2017). These contributions have illustrated that the quality of service should be considered an attitude highly related to satisfaction, but not equivalent (Pansariand Kumar, 2017). The quality of the service can be defined as the degree and direction of the discrepancies between the perceptions of service delivery and the previous expectations of cus-tomers or users (Parasuraman et al., 2002). Currently, most researchers agree that quality serviceis a record of customer satisfaction (Zeithaml et al., 2020).

The use of different instruments such as SERVQUAL, which measures the gaps between expectations and reality, has helped establish explanatory models based in dimensions of qualityservice related to the client's or user's observations and how the client or user finally receives the service delivered (Patel, 2014). In this way, Dehghanpouri et al. (2020) has proposed modelsthat begin with the SERVQUAL measurement scale, consisting of dimensional structures or constructs: tangibles, reliability, responsiveness, assurance, and empathy for measure service quality. Furthermore, this type of conceptual models of the relationship between service qualityand customer satisfaction are developed based on the literature and serve to explore various hypotheses. The above is possible under the approach of SEM, wich emerges as a result ofthe conjunction of two traditions. On the one hand, an econometric perspective focused on prediction, on the other, a psychometric approach that models concepts as latent (unobserved) variables that are indirectly inferred from multiple observed measures (indicators or manifest variables), see Tarka (2018) and Hair et al. (2019). However, generally this dimensions are considered as not correlated with each other, or without interdependence (Jones and Shandiz, 2015).

In the pharmaceutical area, the issue of measuring service quality has been approached from different perspectives. For example, Parmata (2016) proposes a measurement of perceived qual- ity, using a valid scale with four dimensions (reliability, guarantee, responsiveness and com- munication) adapted from SERVQUAL. In other study Maidana et al. (2018), have shown the reliability and validity of the content, the criteria and the conformation of constructs for adap- tations of the SERVQUAL dimensions to the pharmaceutical context of self-services. There is evidence that in the pharmaceutical context, not all dimensions of SERVQUAL tend to have the same importance in determining the quality of service perceived by the user (Pereira et al., 2019). Moreover, it is very likely that there could be interrelationships between some of these dimensions (Khanjankhani et al., 2016).

In this study, we will try the following hypothesis:

- Hypothesis 1: The dimensions of SERVQUAL in the pharmaceutical area have dif- ferent importance in determining the quality of service perceived by the user
- Hypothesis 2: The dimensions of SERVQUAL in the pharmaceutical area have inter- dependence relationships, and together determine the quality of service perceived by the user

Previous research suggests that only measuring the expectations and perceptions of the service are not sufficient to be able to determine consumer satisfaction, so the importance of individual attributes must be identified so that practices as well as management resources can be orientedand properly assigned (Abu-Salim et al., 2017). In this context, the same author has shown thatmen tend to prefer to classify marketing-related stimuli to a more general level of abstraction compared to women. Women tend to focus more on differentiation points, so they will needto use a greater number of descriptors when evaluating products and services. The above, for example, makes women prefer a higher level of personalization in banking services compared tomen. In other context, Hwang et al. (2019) found that women's expectations were significantlyhigher compared to men's, in four of the five dimensions of fast food service quality. The fourdimensions with the highest expectations were: tangibility, reliability, sensitivity and empathy,while security expectations were very similar. Gender is a basic cultural difference related to thedivision of the sexual role in society that has often been overlooked in relation to the evaluation of services. Other study as Ojekalu et al. (2019), found that the gender and education of theoccupants significantly influenced the perception of service quality. Women rated the quality of service of managers better compared to men. However, the age of the occupants did notsignificantly influence the perception of service quality. Other demographics variables such asage and region of residence have not shown consistently robust relationships with the quality ofservice perceived by users, see Fatima et al. (2018),Boah et al. (2020) and Ojekalu et al. (2019)).In the above context, Wajda and $\mathrm{Hu}$ (2004) have shown that men tend to prefer to classify marketing stimuli to a more general level of abstraction than women. Women will tend to fo-cus on differentiation points and will use a greater number of descriptors in their evaluation of products and services. This arguments make us propose the following hypothesis for the area of pharmaceutical services:

- Hypothesis 3: The relationships of interdependence of SERVQUAL dimensions in the pharmaceutical area and the quality of service perceived by the user, are different depending on the gender of the same

The central strategy of relationship management of the organization is the ability of that orga-nization to develop and improve Long-term relationships with users and to satisfy current users. The main focus of such organizations is on user satisfaction and loyalty, that is, to retain their customers / users and generate repeated orders / services (Ozuem et al., 2017).

Patient satisfaction is important because it leads to a higher rate of patient retention and cus-tomer loyalty (Mamalis et al., 2020). A good deal of research has explored a variety of health care service quality dimensions that may influence patient satisfaction, such as continuity of care, physician expertise, the concern shown by the physician 
and other medical staff, and phys-ical facilities, see Wan et al. (2020), Xie and Or (2017),Zaid et al. (2020), however, to our best knowledge, we have not found studies on the relationships between the loyalty of users of a ser-vice, measured by indicators such as the rate of visit of a service and dimensions of perceived quality of service.

Study of Zaid et al. (2020), show that patient satisfaction varies according to the number of outpatient visits he has had. Regarding how this finding relates to SERVQUAL dimensions, the author finds that patients with a low visit rate value the quality of service based mainly on the dimensions of reliability and safety, while the group of patients with the most visit rate, They make based on the dimension of empathy.

This arguments make us propose the following hypothesis for the area of pharmaceutical services:

\section{- Hypothesis 4: Rate of visit of pharmaceutical service is a deter- minant in the rela- tionships of interdependence of SERVQUAL dimensions and the quality of service perceived by the user}

\section{Methodology}

In a structural equation model, each unobservable construct $(\mathrm{C})$ is related to a set of observable items or variables $(\{\mathrm{O} 1, \mathrm{O} 2, \mathrm{O} 3, \ldots, \mathrm{n}\}$, through a linear combination of fix coefficients $(\{\mathrm{f} 1, \mathrm{f} 2, \mathrm{f} 3, \ldots, \mathrm{fn}\}$ added to their respective errors $\left(\left\{\epsilon_{1^{\prime}}, \epsilon_{2^{\prime}} \epsilon_{3^{\prime}}, \epsilon_{n}\right\}\right.$. Mathematically this relation is expressed by:

$$
\begin{gathered}
01=f 1 C+\epsilon_{1^{\prime}} \\
02=f 2 C+\epsilon_{2^{\prime}} \\
03=f 3 C+\epsilon_{3^{\prime}} \\
\cdot \\
0 n=f n C+\epsilon_{n^{\circ}} .
\end{gathered}
$$

By assuming multivariate normality of the variables, the expected value of the term error is null, then $(\mathrm{E}(\epsilon)=0)$. By generating a matrix of standardized data $(Z)$, the factor model can be expressed as a function of $Z$, as (1):

$$
Z=f F S+\epsilon,
$$

with $f$ as a factorial load vector, $\epsilon \sim(0, \psi)$, where $\psi=\mathrm{E}\left(\epsilon_{j} \epsilon_{j}\right)$ for each individual $(j)$ of the sample, and $F S_{j}$ is factorial score for $j$-th individual in the sample. Then, the factorial score ofindividual $j, j$ $=1,2, \cdots, m$ is estimated as $(2)$ :

$$
\hat{F S}=\hat{f}\left(\hat{f} \hat{f}+\hat{\psi}^{-1}\right)^{-1} Z_{j}
$$

for more detail see Thompson and Daniel (1996).

Since the service quality construct is built based on the difference between perceptions and expectations of various dimensions, we have chosen to consider its factorial score as an observ-able variable for each individual that is part of the sample under study. This approach can be consulted in Harrison-Walker (2002).
In this work, we adapt the items of classic SERVQUAL instrument of Parasuraman et al. (1988) to the pharmaceutical environment. Following Harrison-Walker (2002), we applied fac-torial analysis to define the dimensions more relevant in this area. In this way, and after

\begin{tabular}{|c|c|}
\hline Dimension & Perceptions \\
\hline Tangibility & $\begin{array}{l}\text { PT1. Does the pharmacy have clean and organized facilities, } \\
\text { that is, visually pleasing? } \\
\text { PT2. Do the employees wear a presentable uniform? PT3. } \\
\text { Were the prices shown consistent at checkout? } \\
\text { PT4. Was there availability in the products you were looking for? }\end{array}$ \\
\hline Fiability & $\begin{array}{l}\text { PF1. Were the staff prepared to resolve your problems and } \\
\text { requests? } \\
\text { PF2. Were the employees helpful and polite? } \\
\text { PF3. Do you consider that the employees had } \\
\text { the necessary knowledge to answer all your questions? } \\
\text { PF4. Are product returns agile? }\end{array}$ \\
\hline Emphaty & $\begin{array}{l}\text { PE1. Was the service from the staff efficient? PE2. Was the } \\
\text { time to be seen acceptable? } \\
\text { PE3. Were the products offered by the pharmacy of quality? } \\
\text { PE4. Is the pharmacy hours accessible? } \\
\text { PE5. Do you think you received personalized attention at } \\
\text { the pharmacy? PE6. Are the employees friendly and under- } \\
\text { standable to complaints? PE7. Did the pharmacy workers } \\
\text { show full interest in what you needed? }\end{array}$ \\
\hline Dimension & Expectativas \\
\hline Tangibility & $\begin{array}{l}\text { ET1. Do I expect the pharmacy to have clean and organized } \\
\text { facilities, } \\
\text { that is, visually pleasing? } \\
\text { ET2. Do I expect the pharmacy employees to wear a pre- } \\
\text { sentable uniform? } \\
\text { ET3. Do I expect the advertised prices at the pharmacy to be } \\
\text { consistent at checkout? ET4. Do I hope that all the products } \\
\text { I am looking for are available in the pharmacy? }\end{array}$ \\
\hline Fiability & $\begin{array}{l}\text { EF1. Do I expect the pharmacy staff to be prepared to solve } \\
\text { problems and customer requests? } \\
\text { EF2. Do I expect the pharmacy to have helpful and polite } \\
\text { employees? } \\
\text { EF3. Do I hope that the pharmacy has employees with the } \\
\text { necessary knowledge to answer all my questions? } \\
\text { EF4. Do I expect product returns to be agile? }\end{array}$ \\
\hline Emphaty & $\begin{array}{l}\text { EE1. Do I hope that the staff service is efficient at the pharmacy? } \\
\text { EE2. Do I expect the time to be seen is acceptable? } \\
\text { EE3. Do I hope that there are quality products in the phar- } \\
\text { macy? } \\
\text { EE4. Do I hope the pharmacy has accessible hours? } \\
\text { EE5. Do I expect to receive personalized attention at the } \\
\text { pharmacy? } \\
\text { EE6. Do I expect the employees to be kind and understand- } \\
\text { able to complaints? } \\
\text { EE7. Do I expect employees to show full interest in what I need? }\end{array}$ \\
\hline
\end{tabular}
pilot validation of the understanding of each item, we built the instrument shown in Table 1, which measures perceptions and expectations of the quality of service in pharmacy users.

Table 1: Perceptions and Expectations Survey directed to user of the pharmaceutical service(clients and / or patients) 
The subsequent factorial analysis of this group of questions helped us to define the three dimensions of perceptions and expectations of quality of service to study, namely: Tangibility, Fiability and Empathy. This reduction of the classical dimensions in this area is in agreement with the results of previous studies, see Harrison-Walker (2002). We validate all the latent constructs involved for validity and reliability. For this based on its results of confirmatory factorial analysis (CFA), we prove the construct validity using fitness indexes. Then, under a method of variance extraction with varimax rotation to ensure that each extracted factor covered the maximum of variance shared with the original variables that compose it. The criteria that gives account of the indicated areas are: own values $>1$ for each factor, whose sum collects an inertia higher than $70 \%$, with the minimum correlation between factors, confirming the statistical significance of factorial loads with magnitudes greater than 0.7 , and discarding loads $<0.5$. Each question was evaluated with an ordinal measurement scale of 1 to 5 , with N/A = Not applicable/ Do not know. By taking a pilot sample of size 10 individuals, the reliability of the constructs indicated above for perceptions and expectations were estimated separately, examining the Cronbach's alpha statistic.

Subsequently, we study the correlations between the factorial scores of the constructs of per-ception for each dimension of tangibility (PT), fiability (PF) and empathy (PE), and the factorialscore of service quality $(\mathrm{Q})$, as well as the various interrelationships among them. We calcu- late average variance expected (AVE) to show the convergent validity. We also tested the dis- criminant validity by building the discriminant validity index summary. Finally, we show the reliability when calculating the composite realibity $(\mathrm{CR})$ indicator. The values for AVE and CRshould be above 0.5 and 0.6 respectively, see Kashif et al. (2016). Then we propose structural models to relate constructs and execute the estimation of parameters. Based on the results of the structural models, we test hypotheses and describe the results of the interrelationships between the constructs. We select the best model of interrelationships according to goodness of fit criteria around the data.

The reliability of each structural construct was analyzed by the Composite Realibity (CR) measure $>0.7$, which was calculated from (3):

$$
C R=\frac{\left(_{i=1}^{\left.\sum_{n} f_{i}\right)^{2}}\right.}{\sum_{n}^{i=1}{ }^{i}, i_{i=1} i} \quad \psi
$$

where $f_{i}$ and $\varphi_{i}$ are factorial loads and error variance of each factor to respect items $i=1, \ldots, n$ of the construct to be evaluated, respectively. The discriminant validity is characterized by Aver-age Variance Extracted (AVE) given by (4):

$$
A V E=\frac{\sum_{n}{ }_{i=1} f_{i}^{2}}{\sum_{n}^{i=1}{ }_{i}^{i}, i=1{ }^{i}}
$$

whose value must be greater than the square of the correlations product between each pair of constructs. To evaluate the fit of the proposed structural model, the real data matrix was verified with the hypothesized test by means of the $\frac{x^{2}}{D F}$ (degrees of freedom) distribution test $<3$, the DFs were calculated according to 5 :

$$
D F=\left(\begin{array}{c}
n(n+1) \\
2-k
\end{array}\right)
$$

where $n$ is the number of unobservable variables in the model and $k$, the number of unknown parameters to be estimated. Other adjustment measures of the model were evaluated, such as root mean square residue (RMSEA). After confirming the discriminant and convergent validity of thestructural model, it was possible to use the scores of the sum of factors in each construct, in orderto perform a regression analysis that allows us to validate the associations (sign and magnitude)between constructs. The processing of the structural equations was carried out with the AMOS Graphics, SPSS and R software.

\subsection{Size sample and surveys application}

In order to calculate the sample size of the survey application, we originally considered a margin of error of $5 \%$, a $95 \%$ level of reliability, with a $50 \%$ prevalence ratio of the estimated variables and with a confidence interval of $+-1.96 \mathrm{SD}$ (standard deviation). These indicators were achieved with a total of 200 respondents. The study considered public and private pharmacies, including chains and independent located in diverse locations of Mexico. The data set can be consulted at Rojas and Coluccio (2021).

\section{Results of real-world case study of Mexican pharmaceu- ticalarea}

Tables 2, 3, 4, 5 and 6 show a characterization of the sample in type of pharmacy, location, gender, visits per month and age of the respondents, respectively.

Table 2: Characterization of the sample. Respondent's pharmacy type

\begin{tabular}{rr} 
Respondent's pharmacy type & Count \\
\hline Auto-service & 66 \\
Pharmaceutical chain & 112 \\
Classic Pharmacy & 9 \\
Public Hospital Pharmacy & 12 \\
Private Hospital Pharmacy & 1 \\
\hline
\end{tabular}

Total 
Table 3: Characterization of the sample. Respondent location

\begin{tabular}{|c|c|}
\hline Respondent location & Count \\
\hline Abasolo & 2 \\
\hline Acambaro & 1 \\
\hline Apaseo el Alto & 1 \\
\hline Azcapotzalco & 1 \\
\hline Benito Juarez CDMX & 1 \\
\hline Celaya & 2 \\
\hline Comercio & 1 \\
\hline Dolores hidalgo & 1 \\
\hline Dolores Hidalgo & 8 \\
\hline DOLORES HIDALGO & 1 \\
\hline Dolores Hidalgo Gto & 1 \\
\hline Dolores Hidalgo Guanajuato & 2 \\
\hline Durango Durango & 1 \\
\hline Estado de Mexico & 1 \\
\hline Gto & 2 \\
\hline Gto. & 1 \\
\hline Guadalajara & 1 \\
\hline Guadalupe & 1 \\
\hline Guanajuato & 44 \\
\hline Guanajuato capital & 1 \\
\hline Irapuato & 17 \\
\hline Jalisco & 1 \\
\hline Juchitan de Zaragoza Oaxaca & 1 \\
\hline Leon & 22 \\
\hline Monterrey & 1 \\
\hline Nayarit & 1 \\
\hline Panjamo & 2 \\
\hline QUERETARO & 1 \\
\hline romita & 1 \\
\hline Romita & 6 \\
\hline Salamanca & 4 \\
\hline Salvatierra & 4 \\
\hline San Felipe & 3 \\
\hline San Francisco del Rincon & 4 \\
\hline San Jose Iturbide & 1 \\
\hline San juan del rio, queretaro & 1 \\
\hline San Julian & 1 \\
\hline San Miguel de Allende & 2 \\
\hline Silao & 46 \\
\hline Suchiapa & 1 \\
\hline Tuxpan Jalizco & 1 \\
\hline Valle de santiago & 1 \\
\hline Villa Corona & 1 \\
\hline Yuriria & 1 \\
\hline Zacatecas & 1 \\
\hline Zapotlan El Gde.Jal & 1 \\
\hline Total & 100 \\
\hline
\end{tabular}

Table 4: Characterization of the sample. Respondent's gender

\begin{tabular}{rr}
\hline Respondent's gender & Count \\
\hline Masculine & 84 \\
Female & 116 \\
\hline Total & 100
\end{tabular}

Table 5: Characterization of the sample. Number of visits per month of the respondents.

\begin{tabular}{rll}
\hline Number of visits per month & Count \\
\hline $1-2$ & 90 \\
$3-5$ & 34 \\
$>5$ & 14 \\
$<1$ & 62 \\
\hline Total & 100
\end{tabular}

We study the structural model to establish the inter-relationships between dimensions of per-ceptions of SERVQUAL in pharmaceutical area showed in Fig. 1. We considered a method of variance extraction with varimax rotation to ensure that each extracted factor covered the max- imum of variance shared with the original variables that compose it. In this scheme the latent variables that correspond to construct of Tangibility (T), Fiability (F) and Empathy (E), are represented by an oval, whereas the observable variables (PT1, PT2,...,PF1, $\mathrm{PF} 2, \ldots, \mathrm{PE} 1, \mathrm{PE} 2, \ldots)$ thatcorrespond to the questions of each construct are symbolized by rectangles. As we have indi- cated, in this study the factorial score of the quality of service $(\mathrm{Q})$ corresponds to an observablevariable, as well as the visit rate (Rate Visit in the figure 1). In this model the relations between the unidirectional variables are represented by an arrow.

Figure 1: Structural model

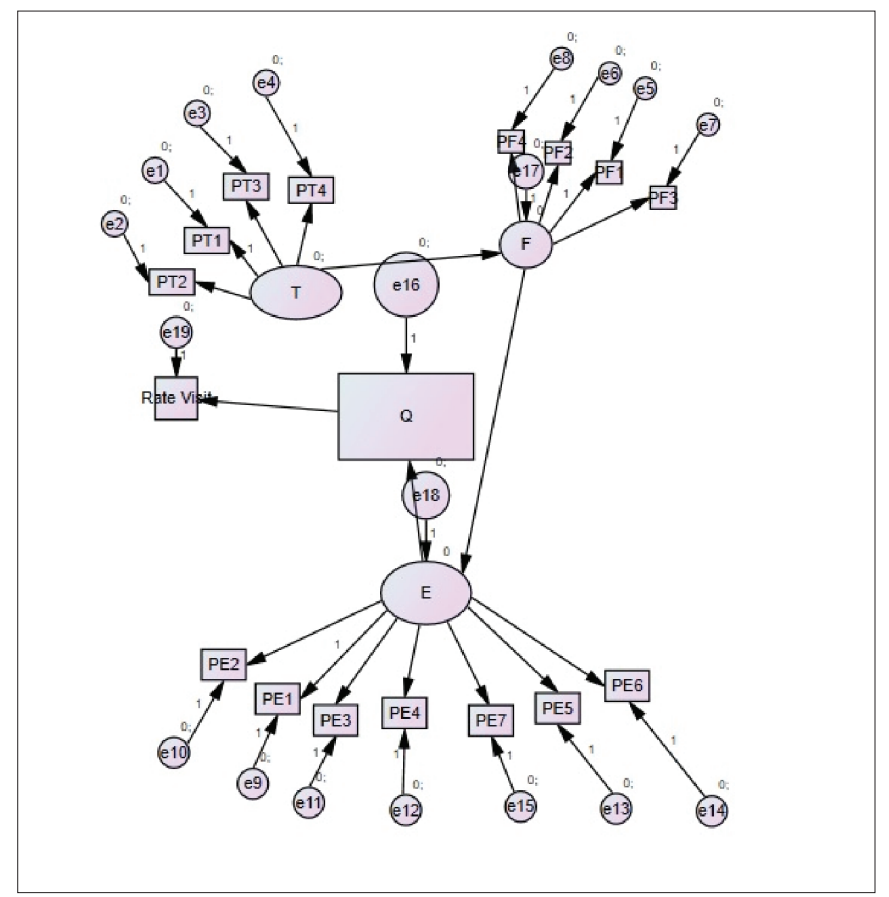


The measurement model was validated through a CFA in the AMOS Graphics and SPSS software. The criteria that gives account of the indicated areas are: own values $>1$ for each factor, whose sum collects an inertia higher than $70 \%$, with the minimum correlation between factors, confirming the statistical significance of factorial loads with magnitudes greater than 0.7 , and discarding loads $<0.5$. The CFA adjustment indicators were: Comparative Fit Index $(\mathrm{CFI})=0.92$, Tucker Lewis index $(\mathrm{TLI})=0.87, \mathrm{RMSEA}=0.094, \chi^{2}(\mathrm{df}=117)=324.09$. In addition, the indicators of average variance extracted (AVE) and Compound reliability (CR) are greater than 0.5 and 0.7 respectively, as shown in Table 8 , granting a good adjustment of the model.

The weight regression estimates, standard error (s.e) and p-values of structural model are shown in Table 9. The intercept estimates, standard error (s.e) and p-values of structural model are shown in Table 10.
We evaluated the interrelationships between the perception constructs of tangibility (T), fi- ability (F) and empathy (E) with the factorial score of service quality $(\mathrm{Q})$ and the rate of visit (Visit Rate) to the pharmacy in Table 11 .

When working the two segments of gender separately, the results differ with the results ob- tained previously. When working with the female segment the same procedure indicated in the previous results, we can note that it has good adjustment rates but with a RMSEA a little higher than the allowed $\left(\mathrm{CFI}=0.90\right.$, TLI $=0.79$, RMSEA $=0.114 ; \chi^{2}(\mathrm{df}=117)=$ 292.122). The weight regression estimates and the statistical significance are shown in table 12. The intercepts and the statistical significance are shown in table 13. As can be seen in table 14, the interrelationships between dimensions of perception of SERVQUAL and factorial scores of quality service and rate of visit to the pharmacy in this segment, have changes.

Table 6: Characterization of the sample. statistical descriptive of age of the respondents.

\begin{tabular}{|c|c|c|c|c|c|c|c|c|}
\hline Charasteristic & mean & sd & IQR & $0 \%$ & $25 \%$ & $50 \%$ & $75 \%$ & $100 \%$ \\
\hline Age & 43.5 & 12.88 & 19.00 & 28.00 & 33.00 & 40.50 & 52.00 & 85 \\
\hline
\end{tabular}

Table 7: Standarized Cronbach Alpha for each dimension of perception and expectation scale

\begin{tabular}{ccc}
\hline Dimension & $\begin{array}{c}\text { Perception } \\
\text { (Standarized Cronbach Alpha) }\end{array}$ & $\begin{array}{c}\text { Expectative } \\
\text { (Standarized Cronbach Alpha) }\end{array}$ \\
\hline Tangibility & 0.84 & 0.93 \\
Fiability & 0.75 & 0.86 \\
Emphaty & 0.93 & 0.97 \\
\hline
\end{tabular}

\section{Discussion}

This study proposes and tests a service quality model based on SERVQUAL dimensions in the Mexican pharmaceutical area. Specifically, we develop a theoretical framework that is basedon interrelationships between the different dimensions of SERVQUAL, assuming that they are not independent of each other. This way of understanding SERVQUAL dimensions can providerelevant information to understand better how individual perceptions affect the service quality inthe pharmaceutical area.

The study of the service quality and the different dimensions of SERVQUAL were carried out in different types of Mexican pharmacies such as public, private, self-service, and hospitals. With these data, a SEM was made. In this model, the dimensions were treated as latent variablesthat interacted in the model. In this sense, our results provide us with valuable information that corroborates our study hypotheses, where the different dimensions interact with each other.

According to the results obtained using SEM, we can point out that the tangibility dimension predicts the fiability dimension. This relationship may be because clients, when they perceive aninfrastructure and equipment by the pharmacy, are more likely to evaluate the service positively. Furthermore, the empathy dimension is predicted by the reliability dimension. This relationship can be explained by the fact that evaluating the service delivered in a better way can be related tomore personalized and individualized service, responding directly to the client's needs. Finally,support was also found on the relationship between service quality and the dimension of empathy. Thus, all these relationships in the proposed study were significant and positive with a $\mathrm{p}<0.01$.These results indicate that the classical look where the dimensions are independent may need tobe revised. In light of the results, we can see a dependency that can explain the clients' quality service evaluation. In this sense, future research should continue to focus on this interdependenceof dimensions and thus be able to understand not only in the pharmaceutical area how these relationships can change and which ones are more important according to the service area that isanalyzed.

Finally, our data provide relevant information on the relationship between the visit rate and gender and the perception of quality in the pharmaceutical area regarding the other proposed relationships. In this sense, our results show us that the visit rate is not related to the perceived quality. These results are contrary to what has generally been found in the literature since cus- tomers perceive a better service quality, repeat the service, and reward the organization for the service delivered, see Chow et al. (2007) . This relationship may not occur in the pharmaceu- tical sector because customers turn to pharmacies, not for pleasure but rather forcibly to buy a drug where this drug is 
the same in all pharmacies. Thus, this choice could generally be based on proximity to where you live or the price of the medicine, but not on the service's perceived quality.

\begin{tabular}{lc}
\multicolumn{1}{c}{ Table 8: AVE and CR for each construct } \\
\hline AVE Tangibility & 0.69 \\
AVE Fiability & 0.54 \\
AVE Empathy & 0.73 \\
CR Tangibility & 0.90 \\
CR Fiability & 0.82 \\
CR Empathy & 0.95 \\
\hline
\end{tabular}

Table 9: Weight regression estimates, $\mathrm{SE}$ and p-values in structural model

\begin{tabular}{lccc}
\hline Relationship & Estimate & S.E. & P \\
\hline PT1 $<-$ T & 1 & & \\
PT2 $<-$ T & 0,936 & 0,083 & $* * *$ \\
PT3 $<-$ T & 0,998 & 0,083 & $* * *$ \\
PT4 <- T & 0,944 & 0,094 & $* * *$ \\
PF1 <- F & 1 & & \\
PF2 <- F & 0,901 & 0,106 & $* * *$ \\
PF3 <- F & 0,866 & 0,119 & $* * *$ \\
PF4 <- F & 0,908 & 0,106 & $* * *$ \\
PE1 <- E & 1 & & \\
PE2 <- E & 1,114 & 0,097 & $* * *$ \\
PE3 <- E & 0,949 & 0,096 & $* * *$ \\
PE4 <- E & 1,118 & 0,096 & $* * *$ \\
PE5 <- E & 0,97 & 0,094 & $* * *$ \\
PE6 <- E & 0,988 & 0,092 & $* * *$ \\
PE7 <- E & 1,107 & 0,095 & $* * *$ \\
\hline
\end{tabular}

Table 10: Intercept estimates, S.E and p-values in the structural model

\begin{tabular}{cccc}
\hline Intercept & Estimate & S.E. & P-Value \\
\hline Q & $-2,483$ & 0,207 & $* * *$ \\
PT1 & 4,08 & 0,069 & $* * *$ \\
PT2 & 4 & 0,069 & $* * *$ \\
PT3 & 4,1 & 0,07 & $* * *$ \\
PT4 & 4,22 & 0,076 & $* * *$ \\
PF1 & 4 & 0,084 & $* * *$ \\
PF2 & 3,735 & 0,075 & $* * *$ \\
PF3 & 3,445 & 0,085 & $* * *$ \\
PF4 & 3,695 & 0,075 & $* * *$ \\
PE1 & 3,56 & 0,075 & $* * *$ \\
PE2 & 3,97 & 0,076 & $* * *$ \\
PE3 & 3,525 & 0,074 & $* * *$ \\
PE4 & 3,87 & 0,075 & $* * *$ \\
PE5 & 3,665 & 0,073 & $* * *$ \\
PE6 & 3,53 & 0,072 & $* * *$ \\
PE7 & 3,595 & 0,074 & $* * *$ \\
Visit & 2,282 & 0,121 & $* * *$ \\
\hline
\end{tabular}

Table 11: Interrelationships estimates, S.E and p-values between constructs

\begin{tabular}{cccc}
\hline $\mathrm{F}<-\mathrm{T}$ & 0,901 & 0,101 & $* * *$ \\
$\mathrm{E}<-\mathrm{F}$ & 0,894 & 0,103 & $* * *$ \\
$\mathrm{Q}<-\mathrm{E}$ & 1,737 & 0,273 & $* * *$ \\
Visit Rate $<-\mathrm{Q}$ & 0,017 & 0,032 & $* * *$ \\
\hline
\end{tabular}

Table 12: Weight regression estimates, $\mathrm{SD}$ and p-values in structural model of female segment

\begin{tabular}{lccc}
\hline Relationship & Estimate & S.E. & P \\
\hline PT1 $<-$ T & 1 & & \\
PT2 $<-$ T & 0.85 & 0.128 & $* * *$ \\
PT3 $<-$ T & 1.132 & 0.131 & $* * *$ \\
PT4 $<-$ T & 0,921 & 0.123 & $* * *$ \\
PF1 <- F & 1 & & \\
PF2 <- F & 1.184 & 0.242 & $* * *$ \\
PF3 <- F & 1.090 & 0.255 & $* * *$ \\
PF4 <- F & 1.1 & 0.225 & $* * *$ \\
PE1 <- E & 1 & & \\
PE2 $<-$ E & 0.988 & 0.151 & $* * *$ \\
PE3 $<-$ E & 0,987 & 0,153 & $* * *$ \\
PE4 $<-$ E & 1.064 & 0,155 & $* * *$ \\
PE5 $<-$ E & 0.956 & 0.147 & $* * *$ \\
PE6 <- E & 0.901 & 0.141 & $* * *$ \\
PE7 <- E & 1.065 & 0.144 & $* * *$ \\
\hline
\end{tabular}

Table 13: Intercept estimates, S.E and p-values in the structural model of female segment

\begin{tabular}{crrc}
\hline Intercept & Estimate & \multicolumn{1}{l}{ S.E. } & P-Value \\
\hline Q & -2.919 & 0.242 & $* * *$ \\
PT1 & 4,129 & 0.080 & $* * *$ \\
PT2 & 4.026 & 0.083 & $* * *$ \\
PT3 & 4.198 & 0.085 & $* * *$ \\
PT4 & 4.362 & 0.080 & $* * *$ \\
PF1 & 4.147 & 0.097 & $* * *$ \\
PF2 & 3.741 & 0.097 & $* * *$ \\
PF3 & 3.457 & 0.109 & $* * *$ \\
PF4 & 3.784 & 0.090 & $* * *$ \\
PE1 & 3.448 & 0.100 & $* * *$ \\
PE2 & 3.991 & 0.096 & $* * *$ \\
PE3 & 3.431 & 0.097 & $* * *$ \\
PE4 & 3.897 & 0.098 & $* * *$ \\
PE5 & 3.733 & 0.094 & $* * *$ \\
PE6 & 3.457 & 0.092 & $* * *$ \\
PE7 & 3.586 & 0.090 & $* * *$ \\
Visit & 2.044 & 0.180 & $* * *$ \\
\hline
\end{tabular}


Table 14: Relationship estimates, S.E and p-values between constructs in female segment

\begin{tabular}{rlll}
\hline $\mathrm{F}<-\mathrm{T}$ & 0.641 & 0.133 & $* * *$ \\
$\mathrm{E}<-\mathrm{F}$ & 1.238 & 0.253 & $* * *$ \\
$\mathrm{Q}<-\mathrm{E}$ & 3.084 & 0.394 & $* * *$ \\
Visit $<-\mathrm{Q}$ & -0.012 & 0.046 & 0.802 \\
\hline
\end{tabular}

Another interesting finding from this study is that the relationships described seem to change with the gender of the respondents. Previous SERVQUAL studies corroborate this finding, see Mensah and Mensah (2018). According to the results obtained, we can see that the interceptof the service quality factor scores is more negative for the female segment, which generally indicates that the difference between the perception and expectations of service quality is worse evaluated in this segment. The above indicates that this genre is more demanding in its evalua- tions of quality of service in the pharmaceutical area. Also note that the relationships between tangibility and fiability are lower in women, however, once this barrier is overcome, the relation-ships between reliability and empathy, and later between empathy and the factor scores of the quality service are higher in this gender, with respect to of men.

\section{Acknowledgements}

This research was partially funded by " Grants-FONDECYT 11190004" of the National Com-mission for Scientific and Technological Research (CONICYT) government of Chile.

\section{References}

Abu-Salim, T., Onyia, O. P., Harrison, T., and Lindsay, V. (2017). Effects of perceived cost, service quality, and customer satisfaction on health insurance service continuance. Journalof Financial Services Marketing, 22(4):173-186.

Boah, M., Adampah, T., Jin, B., Wan, S., Mahama, A. B., Hyzam, D., and Akiti, C. (2020). âi couldnât buy the items so i didnât go to deliver at the health facilityâ home delivery amongrural women in northern ghana: A mixed-method analysis. PloS one, 15(3):e0230341.

Chow, I. H.-s., Lau, V. P., Lo, T. W.-c., Sha, Z., and Yun, H. (2007). Service quality in restaurant operations in china: Decision-and experientialoriented perspectives. International Journal of Hospitality Management, 26(3):698-710.

Dehghanpouri, H., Soltani, Z., and Rostamzadeh, R. (2020). The impact of trust, privacy and quality of service on the success of e-crm: the mediating role of customer satisfaction. Journal of Business \& Industrial Marketing.

Fatima, T., Malik, S. A., and Shabbir, A. (2018). Hospital healthcare service quality, patient satisfaction and loyalty. International Journal of Quality \& Reliability Management.

Grönroos, C. (2020). service marketing research priorities. Journal of Services Marketing, 34(3):291-298.
Hair, J. F., Risher, J. J., Sarstedt, M., and Ringle, C. M. (2019). When to use and how to report the results of pls-sem. European business review.

Haming, M., Murdifin, I., Syaiful, A. Z., and Putra, A. H. P. K. (2019). The application of servqual distribution in measuring customer satisfaction of retails company. The Journal of Distribution Science, 17(2):25-34.

Harrison-Walker, J. L. (2002). Examination of the factorial structure of service quality: a multi-firm analysis. Service Industries Journal, 22(2):59-72.

Hwang, J., Lee, J.-S., and Kim, H. (2019). Perceived innovativeness of drone food delivery services and its impacts on attitude and behavioral intentions: The moderating role of gender and age. International Journal of Hospitality Management, 81:94-103.

Jones, J. L. and Shandiz, M. (2015). Service quality expectations: Exploring the importance of servqual dimensions from different nonprofit constituent groups. Journal of Nonprofit \& Public Sector Marketing, 27(1):48-69.

Kashif, M., Samsi, S. Z. M., Awang, Z., and Mohamad, M. (2016). Exq: measurement of health-care experience quality in malaysian settings: A contextualist perspective. International Journal of Pharmaceutical and Healthcare Marketing, 10(1):27-47.

Khanjankhani, K., Rafiei, S., Ezzatabadi, M. R., Askari, R., Abooee, F., and Shafii, M. (2016). Evaluation and prioritization of service quality dimensions using dematel and topsis (a casestudy in iran). Bali Medical Journal, 5(2):118-123.

Maidana, G. M., Lugo, G. B., Samaniego, L., Lial, N., Acosta, P., and Vera, Z. (2018). Eval- uación del servicio de farmacia que atiende a pacientes diabéticos. Pharmaceutical Care España, 20(3).

Mamalis, S., Kamenidou, I., Pavlidis, S., and Xatziaggelou, A. (2020). Perceptions of hospital quality: A case study from greece. In Strategic Innovative Marketing and Tourism, pages 403-410. Springer.

Mensah, I. and Mensah, R. D. (2018). Effects of service quality and customer satisfaction on repurchase intention in restaurants on university of cape coast campus. Journal of Tourism, Heritage \& Services Marketing, 4(2):27-36.

Ojekalu, S. O., Ojo, O., Oladokun, T. T., and Olabisi, S. A. (2019). Effect of demographic characteristics on service quality perception: Evidence from occupiers of shopping complexin ibadan, nigeria. Property Management, 37(3):418-431.

Ozuem, W., Patel, A., Howell, K. E., and Lancaster, G. (2017). An exploration of consumers' response to online service recovery initiatives. International Journal of Market Research, 59(1):97-115.

Pansari, A. and Kumar, V. (2017). Customer engagement: the construct, antecedents, and conse- quences. Journal of the Academy of Marketing Science, 45(3):294-311. 
Parasuraman, A., Zeithaml, V., and Berry, L. (2002). Servqual: a multiple-item scale for mea- suring consumer perceptions of service quality. Retailing: critical concepts, 64(1):140.

Parasuraman, A., Zeithaml, V. A., and Berry, L. (1988). Servqual: A multiple-item scale for measuring consumer perceptions of service quality. 1988, 64(1):12-40.

Parmata, U. M. D. (2016). Measuring service quality in pharmaceutical supply chain distrib- utors perspective. International Journal of Pharmaceutical and Healthcare Marketing, 10(3):258-284.

Patel, K. (2014). Validating the servqual scale and its effect on brand loyalty: A study in indianretail banking context. International Journal of Retailing \& Rural Business Perspectives, 3(3):1098.

Pereira, A. M. V., Macri, L. M. S. R., Olivera, M. M., and Costa, Y. P. D. (2019). Application of servqual for evaluation of quality of care in a pharmacy situated in the city of pau dos ferros-rn. Research, Society and Development, 8(6):1086881.

Rojas, F. and Coluccio, G. (2021). SERVQUAL model with interrelated dimensions. The case of the pharmacy in Mexico. Data set.

Rojas, F., Coluccio, G., and Vega, J. (2018). Relationships between supply performance of pharmacies in chile and their quality of customer service. International Journal of Pharma-ceutical and Healthcare Marketing.

Shafiq, M., Naeem, M. A., Munawar, Z., and Fatima, I. (2017). Service quality assessment of hospitals in asian context: An empirical evidence from pakistan. INQUIRY: The Journal of Health Care Organization, Provision, and Financing, 54:0046958017714664.

Song, J. and Qu, H. (2017). The mediating role of consumption emotions. International Journalof Hospitality Management, 66:66-76.

Tarka, P. (2018). An overview of structural equation modeling: its beginnings, historical devel-opment, usefulness and controversies in the social sciences. Quality \& quantity, 52(1):313-354.

Thompson, B. and Daniel, L. G. (1996). Factor analytic evidence for the construct validity of scores: A historical overview and some guidelines.
Tzeng, G.-H. and Chang, H.-F. (2011). Applying importance-performance analysis as a servicequality measure in food service industry. Journal of technology management \& innovation,6(3):106-115.

Um, Ki Hyun \& Lau, A. K. (2018). Healthcare service failure: how dissatisfied patients respondto poor service quality. International Journal of Operations \& Production Management.

Vatjanasaregagul, L. (2019). The relationship of trust, satisfaction, commitment and loyalty.

Journal of Administration and Management, 9(2):143-162.

Wajda, T. A. and Hu, M. (2004). Gender differences in cognitive structure: Preferred levels of taxonomic abstraction. ACR Gender and Consumer Behavior.

Wan, Y., Zhang, Y., and Yan, M. (2020). What influences patients' willingness to choose in online health consultation? an empirical study with pls-sem. Industrial Management \& Data Systems.

Xie, Z. and Or, C. (2017). Associations between waiting times, service times, and patient satisfaction in an endocrinology outpatient department: a time study and questionnaire survey. INQUIRY: The Journal of Health Care Organization, Provision, and Financing, 54:0046958017739527.

Zaid, A. A., Arqawi, S. M., Mwais, R. M. A., Al Shobaki, M. J., and AbuNaser, S. S. (2020). The impact of total quality management and perceived service quality on patient satisfaction andbehavior intention in palestinian healthcare organizations. Technology Reports of Kansai University, 62(03):221-232.

Zeithaml, V. A., Jaworski, B. J., Kohli, A. K., Tuli, K. R., Ulaga, W., and Zaltman, G. (2020). A theories-in-use approach to building marketing theory. Journal of Marketing, 84(1):32-51. 
